\title{
Abordagem Terapêutica da Dor Neuropática na Clínica Neurológica
}

\author{
Acary de Souza Bulle Oliveira*, Alberto Alain Gabbai**
}

\section{RESUMO}

Neste trabalho os autores descrevem as drogas e os procedimentos mais utilizados para analgesia em neurologia e depois apresentam uma abordagem prática para a dor que surge em pacientes com as diversos tipos de neuropatia periférica.

\section{UNITERMOS}

Dor, analgésicos, neuropatia periférica.
Chefe do Setor de Doenças Neuromusculares da Escola Paulista de Medicina UNIFESP.

** Professor Titular de Neurologia da Escola Paulista de Medicina - UNIFESP.

\section{CONSIDERAÇÕES GERAIS}

A dor, um dos sintomas psicofísicos mais freqüentes dentro da medicina, é um fenômeno tão complexo, tão ligado ao ser humano, que nos permite considerá-la parte inerente da própria estrutura humana.

A Associação Internacional para o Estudo da Dor define-a como "uma sensação desagradável com sofrimento emocional associada com lesão tecidual real ou potencial, ou delineada em termos de tal lesão".

O existir ou coexistir com a dor é antigo como a humanidade e ela pode ser valorizada e quantificada sob as mais diferentes formas. A sua percepção em um determinado indivíduo permanece muito subjetiva e relaciona-se com o insulto nociceptivo sob uma maneira muito complexa e pobremente entendida. Como a dor tem o seu elemento afetivo, condições psicológicas assumem grande importância em todos os estados de dor persistente. Além do mais, a tolerância à dor e a capacidade de senti-la sem verbalizar são também influenciadas por raça, sexo, cultura e religião. Nos orientais, ela é relacionada a um fenômeno humano com o qual temos que conviver. Da mesma forma, a sua intensidade durante uma guerra é considerada bem menor do aquelas causadas em situações mais usuais ou banais. Por outro lado, geralmente as mulheres reportam dor mais intensa e utilizam mais e maiores dosagens de medicamentos que os homens. Por isso, por sua presença tão freqüente no cotidiano do indivíduo, não é difícil entender que a preocupação inicial da medicina sempre foi atenuar a dor, e o grande número de avanços feitos na terapêutica médica pode ser atribuído em parte à diversidade de substâncias capazes de aliviá-la ou, até mesmo, de eliminá-la. É fundamental, entretanto, que o médico perceba que é uma pessoa que ele está tratando, não simplesmente um sintoma.

O conceito simplista de dor como dependente da ativação direta de um sistema de projeção caminhando da periferia até o córtex não pode ser mais aceito. O processo doloroso depende também de um sistema complexo de modulação de sinal através do sistema nervoso central (SNC). Clinicamente observa-se que os pacientes que apresentam um quadro de dor aguda têm melhor resposta terapêutica que pacientes com dores prolongadas. Ầ medida 
que um quadro doloroso evolui de agudo para subagudo ou crônico (arbitrariamente definido como aquele que excede 6 meses de dor continuada), ele deixa de ser dependente de alguma alteração periférica e passa a ser sustentado por alguma alteração do SNC. Como resultado tem-se o desenvolvimento não mais de um traço de hipersensibilidade ou hiperalgesia transitória, mas de hiperalgesia permanente. Ou seja, o neurônio envolvido está alterado para o resto da vida dele, pelo número de anos que este indivíduo sobreviver. Nessas situações, o insucesso terapêutico é a regra, não uma exceção ${ }^{8}$.

Avanços no entendimento da neurofarmacologia e neurofisiologia da dor têm permitido bases mais racionais para o seu tratamento.

\section{TIPOS DE DOR}

A dor aguda é considerada como parte do nosso sistema nociceptivo, o sistema de defesa que prontamente alerta o corpo para influências externas danosas, originada através da estimulação das terminações nervosas que contêm os nociceptores. Imagina-se que a dor aguda, penetrante, facilmente localizável, seja transmitida pelas fibras nervosas finas A delta de condução rápida $(15 \mathrm{~m} / \mathrm{s})$. A dor crônica, descrita como surda, amolante, em queimação e de difícil localização, é mediada pelas fibras $\mathrm{C}$, pobremente mielinizadas (velocidade de condução de $1 \mathrm{~m} / \mathrm{s}$ ).

Dependendo da sua origem, a dor pode ser classificada em somática, visceral e neuropática. Os três tipos de dor são mediados por redes neuronais e vias neuroanatômicas distintas. Dor somática ou "nociceptiva" é uma conseqüência de lesão tecidual, tais como em osso, músculo, tendão ou ligamento. Dor somática é típica e bem localizada, freqüentemente familiar ao paciente e descrita com facilidade. Dor visceral tipicamente resulta de trauma, inflamação, infecção ou tumor em tórax ou vísceras abdominais. Ela é pobremente localizada e com frequiência referida em diferentes sítios cutâneos (por exemplo dor no ombro ocasionada por irritação diafragmática em colecistite). Dor neuropática é uma conseqüência de lesão neuronal.

\section{DOR NEUROPÁTICA}

O termo dor "neuropática" restringe-se necessariamente aos pacientes com lesão orgânica do nervo periférico com alterações secundárias do corno posterior da medula e/ou dor mantida por alterações simpáticas.
Pode ser dividida em dois principais tipos, que podem coexistir ou não: dor disestésica e dor de tronco nervoso.

A dor disestésica, também chamada de dor por deaferentação, é característica da causalgia e das polineuropatias com envolvimento de fibras nervosas de pequeno calibre. Tipicamente, é referida como uma sensação desagradável, como queimadura ou choque, freqüentemente não familiar para o paciente, localizada de preferência nas porções distais dos membros. Dor disestésica não envolve nociceptores, característica esta que pode explicar sua forma peculiar de apresentação, além da ineficácia usual da atuação de medicamentos.

A dor de tronco nervoso, exemplificada pelos casos de compressão radicular (por exemplo, hérnia de disco), é definida como uma dor tipo facada, profunda, relativamente proximal, familiar, semelhante a uma dor de dente, freqüentemente contínua, que piora com movimento e melhora com repouso.

\section{CONDUÇÃO E PROCESSAMENTO DA DOR}

A anatomia e a fisiologia da dor foram amplamente estudadas e, como se sabe, as vias que conduzem a dor têm numerosas interconexões com outras vias aferentes nociceptivas e fibras nervosas simpáticas ${ }^{1}$.

Sabe-se que o neurônio nociceptivo periférico utiliza dois neurotransmissores: o glutamato, que é o principal responsável pela ativação do neurônio pós-sináptico, e a substância $P$, que tem uma função moduladora e ajusta a sensibilidade do neurônio pós-sináptico à atividade do glutamato. Este tem três tipos de receptores, sendo que os receptores tipo NMDA e tipo AMPA estão envolvidos com o processo de dor. O receptor AMPA é responsável por um potencial pós-sináptico rápido e fugaz, permitindo que os recptores NMDA fiquem operantes. Quando o glutamato é liberado ele ativa o receptor NMDA, o canal de cálcio é aberto e há um enorme fluxo de cálcio para dentro da célula ${ }^{7}$.

\section{DOR E SISTEMA NERVOSO SIMPÁTICO}

As fibras aferentes simpáticas caminham pelos ramos brancos comunicantes do tronco simpático até as raízes posteriores da medula espinhal, explicando-se, portanto, o importante papel do sistema nervoso simpático de gerar, modular e conduzir a informação produzida pelos estímulos dolorosos. 
O sistema nervoso simpático pode estar envolvido nas síndromes dolorosas, especialmente na dor por deaferentação, como encontrado na síndrome de dor regional complexa (SDRC).

A SDRC representa entidades distintas com dor mediada simpateticamente. Caracteriza-se pela presença de dor regional e alterações sensitivas seguindo um evento prejudicial. Além do mais, a dor está associada com anormalidades da cor da pele, alterações da temperatura, atividade sudamotora anormal ou edema. A combinação desses achados excede sua magnitude esperada em resposta a lesão física conhecida durante e seguindo o evento inicial. Dois tipos de SDCR têm sido reconhecidos: tipo I, que corresponde à distrofia simpático reflexa e ocorre sem uma lesão de nervo reconhecida, relacionada com traumas menores repetitivos, imobilização, acidente vascular cerebral, infarto do miocárdio; tipo II, ou causalgia, refere-se aos casos onde há uma lesão definida de nervo. SDRC tipo I, tipicamente, tem dor profunda, difusa, que piora com dependência da posição do membro (ortostática), a qual pode responder a bloqueio simpático. SDRC tipo II tradicionalmente relaciona-se com lesões envolvendo grandes nervos, como o nervo mediano ou o nervo ciático ${ }^{11}$.

\section{CONSIDERAÇÕES TERAPÊUTICAS}

Para uma orientação terapêutica adequada da dor é preciso seguir basicamente duas premissas: reconhecimento e tratamento de sua causa, e alívio do sintoma doloroso tão rápido quão possível para uma recuperação completa. Em princípio, a dor pode ser tratada de quatro maneiras: por drogas, por métodos invasivos, por métodos físicos e psicoterapia ${ }^{5}$.

\section{Drogas}

A terapia por drogas inclui tanto a administração sistêmica de medicamentos como procedimentos anestésicos locais ou de administração intratecal de determinadas drogas.

A escolha de um medicamento específico demanda consideração cuidadosa, especialmente ao se tratar de dor crônica. A maioria dos problemas decorrentes da prescrição e uso de medicamentos analgésicos é encontrada nesta categoria, porque o que se pretendia ser um tratamento a curto prazo facilmente pode transformar-se em longo prazo ou em uma necessidade permanente. $\mathrm{O}$ uso diário por um certo período de tempo de determinados medicamentos, incluindo-se os aparentemente inofensivos analgésicos, nunca deve ser permitido a menos que orientado por um médico. Todos os médicos experientes estão familiarizados com o problema. As dificuldades mais críticas surgem nos pacientes jovens, que desejam levar uma vida social ativa e são impedidos de fazê-lo. O uso a longo prazo de analgésicos, especialmente os mais potentes, pode levar a vários problemas, incluindo-se o desenvolvimento de tolerância, ou mesmo ao surgimento de dependência à droga. A tolerância e a velocidade de seu desenvolvimento são imprevisíveis.

O insucesso terapêutico seria evitado através de apropriada avaliação clínica, neurológica e psiquiátrica. Drogas específicas não serão úteis se dadas para o paciente errado.

\section{Bases fundamentais para o uso de drogas em neurologia}

Os maiores determinantes para o sucesso terapêutico com drogas em neurologia consistem: no conhecimento do local de atuação da droga no sistema nervoso; na facilidade destas de atravessar a barreira hematoencefálica; no conhecimento da absorção, distribuição e metabolismo delas; no reconhecimento da toxicidade ou dos efeitos adversos; e idade do paciente. Os principais sítios de atuação podem ser divididos em 4 categorias: sinapse química entre os neurônios; outros neurônios não envolvidos em sinapse; outras células dentro do sistema nervoso, tais como a célula da glia e vasos sangüíneos; ácido nucléico e maquinaria de síntese protéica. As drogas analgésicas podem ser divididas em três principais classes para o propósito desta abordagem: 1) aspirina e outros analgésicos antiinflamatórios não hormonais, os quais atuam nas terminações nervosas dos sítios de lesão e produzem analgesia por alterar o sistema das prostaglandinas; 2) analgésicos narcóticos (opióides), os quais atuam por se ligar a receptores opióides e ativar o sistema de supressão endógeno da dor no SNC; e 3) analgésicos "auxiliares", os quais atuam centralmente para produzir analgesia em certos tipos de dor. A escolha de uma droga específica baseia-se na valorização da síndrome dolorosa, na severidade da dor e no entendimento da farmacologia clínica dos analgésicos específicos.

Os analgésicos antiinflamatórios não hormonais e os analgésicos narcóticos são mais efetivos no controle da dor aguda. O uso de analgésico narcótico deve ser reservado para os casos de dor de causa tumoral, onde o desenvolvimento de tolerância e a possível emergência do vício são de menor importância, secundária nesses casos. A dor neuropática freqüentemente 
apresenta resposta desfavorável ao uso de morfina ou outros opióides, necessitando-se de doses maiores e com os consequientes efeitos adversos. Os analgésicos "auxiliares", como anticonvulsivantes, antidepressivos, neurolépticos e corticóides são as drogas de escolha para os casos de dor neuropática, especialmente aquelas por deaferentação. Nos casos em que são eficazes, eles têm a grande vantagem de não induzir tolerância e não causar dependência. Ainda, embora menos comumente, outras drogas como o baclofen e o prazosin podem ser utilizadas no combate da dor de causa neuropática ${ }^{9}$.

\section{Principais drogas utilizadas}

Analgésicos não opióides: ao escolher um analgésico, o médico deve ponderar os benefícios esperados contra os riscos adversos de seu uso. Nos casos de dor aguda severa, os analgésicos devem sempre ser tomados sob supervisão médica, desde que o diagnóstico da doença subjacente responsável tenha sido estabelecido.

Paracetamol (Acetofen ${ }^{\circledR}$, Dôrico $^{\circledR}$, Tylenol $^{\circledR}$ ): este é um analgésico e antipirético que não tem propriedades antiinflamatórias, mas que pode ser usado em casos de dor ocasionada por tumor. A dose recomendada é de 0.5 a 1 grama de $4-4$ horas.

Antiinflamatórios não hormonais (AINH): os AINH são provenientes de uma grande variedade de classes químicas (salicilatos, acetatos, propionatos, oxicans). A resposta terapêutica é variável e dependente das pequenas diferenças nas suas propriedades físicoquímicas, farmacocinéticas e mecanismos de ação.

Analgésicos narcóticos: o emprego de drogas opiáceas para alívio da dor, sobretudo a de causa oncológica, foi uma grande conquista. Há muito sabese que os derivados de morfina exercem ação direta sobre unidades celulares da medula espinhal e do tronco encefálico que suprimem a atividade nociceptiva. Ao usar opiáceos ou opióides, o risco de dependência está sempre presente. Ainda, nas doses comumente usadas, é provável que a morfina e outros narcóticos administrados por via sistêmica alcancem, no SNC, concentrações altas e atuem em vários tipos de receptores opiáceos; resultam em analgesia e vários efeitos adversos, tais como obstipação intestinal, retenção urinária, prurido, disforia ou sonolência.

Opióides fracos: codeína $\left(\right.$ Belacodid $^{\circledR}$, Setux $^{\circledR}$, Tylex ${ }^{\circledR}$ ), destropropoxifeno (Algafan ${ }^{\circledR}$, Doloxene $A^{\circledR}$ ).

Opióides fortes: morfina é freqüentemente o opióide deste grupo mais usado. Pode ser dado sob a forma oral (Dimorf $^{\circledR}-10$ a $30 \mathrm{mg}$; Sylador ${ }^{\circledR}$, Temgesic $^{\circledR} 0,2 \mathrm{mg}$; Tramal ${ }^{\circledR} 50 \mathrm{mg}$ ), via subcutânea ou endovenosa (Dimorf sol inj ${ }^{\circledR}-10 \mathrm{mg}$; Tramal ${ }^{\circledR}$ ). A posologia é variável de paciente para paciente, recomendando-se não ultrapassar o uso de 8 comprimidos ou 4 ampolas ao dia. Metadona pode ser a melhor escolha em pacientes com intolerância a morfina. $\mathrm{O}$ risco de toxicidade é maior em pacientes com comprometimento renal e hepático. Petidina (Demerol $^{\circledR}$ - 50 a $150 \mathrm{mg}$ de $4-4$ horas) e meperidina (Dolantina $^{\circledR}-100 \mathrm{mg}$ ) podem ser efetivas, mas são extremamente neurotóxicas, especialmente nos idosos, causando agitação, disforia, tremores e, ocasionalmente, convulsões. Fentanil, um potente opióide sintético, pode ser usado sob a forma de "patch" subcutâneo (Duragesic ${ }^{\circledR}$ ) ou por via endovenosa $\left(\right.$ Fentanil $\left.{ }^{\circledR}\right)$.

Anticonvulsivantes: os anticonvulsivantes atuam através de seu efeito anestésico local com estabilização da membrana neuronal, diminuição da transmissão sináptica e supressão da atividade espontânea que pode ocorrer no aferente primário e gânglio da raiz dorsal. São indicados principalmente em situações onde lesões nervosas parciais ou totais causam desequilíbrio entre os impulsos aferentes e os mecanismos de modulação, como, por exemplo, na dor por deaferentação. A carbamazepina (Tegretol ${ }^{\circledR} 400$ a $800 \mathrm{mg} /$ dia ou mais) é a droga de escolha no tratamento de qualquer neuropatia periférica dolorosa. Outros anticonvulsivantes úteis incluem fenitoína (Hidantal ${ }^{\circledR} 100$ a $300 \mathrm{mg} / \mathrm{dia}$ ), valproato (Depakene ${ }^{\circledR} 250$ a $1500 \mathrm{mg} / \mathrm{dia}$ ) e clonazepam (Rivotril ${ }^{\circledR} 1$ a $6 \mathrm{mg} / \mathrm{dia}$ ). Essas drogas devem ser utilizadas em dosagens fracionadas, em horários predeterminados.

Antidepressivos: o seu mecanismo de ação ainda não está claro, mas pode ser relacionado com o bloqueio da recaptação da serotonina e da norepinefrina, aumentando a atividade dessas monoaminas nos terminais das vias de modulação da dor. A amitriptilina (Tryptanol ${ }^{\circledR} 10$ a $125 \mathrm{mg} /$ dia), um antidepressivo tricíclico, possui a melhor ação analgésica documentada, mas suas ações anticolinérgicas, tais como boca seca, hipotensão ortostática e retenção urinária, além de delírio, podem limitar o seu uso. Pacientes idosos também são muito sensíveis às ações dos tricíclicos; o tratamento deve ser iniciado em doses mais baixas e com aumento gradual. Outros tipos de antidepressivos como imipramina $\left(\right.$ Tofranil $\left.^{\circledR}\right)$, nortriptilina $\left(\right.$ Pamelor $\left.^{\circledR}\right)$, clomipramina $\left(\right.$ Anafranil ${ }^{\circledR}$ ), doxepina (Sinequan ${ }^{\circledR}$ ) e fluoxetina $\left(\operatorname{Prozac}^{\circledR}\right.$, Eufor $^{\circledR}$, Daforin ${ }^{\circledR}$ ) também têm sido usados especialmente em síndromes dolorosas crônicas.

Neurolépticos: fenotiazinas (clorpromazina Amplictil ${ }^{\circledR} ;$ flufenazina - Anatensol ${ }^{\circledR}$ ) têm sido utilizadas, particularmente em associação com os antidepressivos tricíclicos, no tratamento de neuropatias 
dolorosas, tais como neuropatia pelo diabetes e neuralgia pós-herpética. O seu uso contínuo é limitado pelo aparecimento freqüente de discinesias tardias.

Corticosteróides: os corticosteróides, através de sua ação supressora de descargas ectópicas, também são usados na forma de dor neuropática. Particularmente, podem ser utilizados no tratamento da síndrome de dor regional complexa e nos tumores de crescimento rápido. Dexametasona (Decadron ${ }^{\circledR}$ ) é o agente mais usualmente empregado (inicialmente 2 a $8 \mathrm{mg} \mathrm{12-12}$ horas). Prednisona (Meticorten ${ }^{\circledR}$ ) de 25 a $75 \mathrm{mg}$ diariamente é uma alternativa terapêutica.

Vitaminas: embora vitaminas do grupo B sejam freqüentemente utilizadas no tratamento das neuropatias das mais diferentes causas, há pequena evidência para justificar o seu uso tão generalizadamente. Estas devem ficar restritas àquelas situações onde há deficiência nutricional e vitamínica.

Gangliosídeos: os gangliosídeos, tais como o Cronaxial $^{\circledR}$ e o Sinaxial ${ }^{\circledR}$, muito utilizados na última década, não têm demonstrado uma melhor evolução das neuropatias nem, tampouco, um melhor controle do quadro doloroso. Além do mais, há certos casos descritos na literatura com síndrome de Guillain-Barré associados com o uso prévio dessas substâncias.

\section{Outras drogas}

Calcitonina: a calcitonina de salmão (Miacalcic ${ }^{\circledR}$ ) (200 UI em $500 \mathrm{ml}$ de soro fisiológico a $0,9 \% \mathrm{EV}$ em 1 hora, diariamente, por 20 dias) tem sido utilizada como droga analgésica, sobretudo em casos de metástases ósseas, devido a sua ação analgésica central, que é independente do sistema receptor opiáceo. Entretanto, a sua eficácia depende do tipo de tumor e do sítio da doença metastática.

Capsaicina: capsaicina é um amido fenólico obtido de várias espécies de capsicums que, quando usado sob aplicação tópica a $0,025 \%\left(\right.$ Infrarub $^{\circledR}$ ), pode mostrar efeito benéfico em certos pacientes com dor neuropática, incluindo-se neurite herpética e neuropatia relacionada a AIDS.

\section{Procedimentos invasivos}

Bloqueio simpático: o sistema nervoso autonômico, principalmente simpático, como demonstrado anteriormente, está envolvido com a fisiopatologia de diversas síndromes dolorosas. A supressão temporária de sua ação, através de bloqueios com anestésico local, substâncias neurolíticas ou medicação por via intravenosa, tem sido opção terapêutica de eficiência comprovada.
Simpactetomia: é reservada especialmente para aqueles casos de síndrome de dor regional complexa (SDRC). Ocasiona um alívio sintomatológico em torno de $70 \%$ a $80 \%$. A patogênese desta síndrome é obscura, mas sugere-se que resulta de uma transmissão direta de estímulos nervosos das fibras autonômicas eferentes e as fibras sensitivas dolorosas aferentes, o que poderia justificar a melhora após simpatectomia.

Bloqueio de nervo periférico: bloqueio dos nervos periféricos com substâncias neurolíticas (álcool, fenol, clorocresol, glicerol, solução salina hipertônica) tem sido cada vez menos utilizado e só deve ser indicado em situações excepcionais. No passado, acreditava-se que a interrupção de vias resultaria em alívio permanente da dor. O conhecimento da fisiopatologia da dor por deaferentação veio mostrar que seu efeito terapêutico é temporário, uma vez que a deaferentação por si própria pode causar dor de controle mais difícil que da lesão inicial.

Lidocaína intravenosa: administração de lidocaína intravenosa tem sido utilizada com certa freqüência para produção de analgesia em pacientes com diferentes etiologias de dor neuropática. A dosagem é variável, mas pode ser utilizada até dosagem de $8,35 \mathrm{mg} / \mathrm{min}(500$ $\mathrm{mg}$ em $250 \mathrm{ml}$ de solução salina) durante 60 minutos. Dentre os efeitos adversos incluem-se nistagmo, escurecimento visual transitório, sonolência. Vários autores têm demonstrado uma produção de analgesia prolongada (dias a semanas) após a administração IV de lidocaína. Os mecanismos de ação não estão completamente esclarecidos. Sugere-se predominância de atuação no SNC em relação ao SNP.

Bomba de infusão: o uso de bomba mecânica Cecor Cordis acoplada a cateter implantado no espaço subaracnóideo (L3-L4) ou de bomba eletrônica externa Synchromed Meditronic acoplada a cateter ventricular tem permitido o uso com maior segurança de opiáceos intratecal ou de outros agentes analgésicos, minimizando os efeitos colaterais e propiciando maior analgesia ${ }^{3}$. As bombas eletrônicas são as ideais pois permitem regular a infusão, contínua ou em "bolos", proporcionando a administração harmônica adaptada a cada situação do paciente. Porém, são altamente dispendiosas.

Estimulação da medula espinhal: alguns pacientes com dor neuropática apresentam melhora após a colocação de eletrodos que estimulam eletricamente a medula espinhal. Os maiores problemas são o movimento dos eletrodos no canal espinhal e cicatrização ao redor deles, diminuindo a eficácia.

Procedimentos neurocirúrgicos: incluem rizotomia dorsal e cordotomia cervical (anterolateral) percutânea. 


\section{Métodos físicos}

Muitos pacientes apresentam redução na percepção a dor após estimulação com calor, frio, massagem, vibração, imersão, acupuntura ou eletricidade. Os mecanismos não são completamente conhecidos; poderiam ser em parte por atuação no sistema controlador da dor na medula espinhal ou relacionados com processos neuro-humorais na medula espinhal ou no cérebro.

TENS (Transcutaneous Electrical Nerve Stimulation): estimulação com baixas frequiências tem sido correlacionada com ativação de fibras nervosas de pequeno calibre via limiar térmico, e estimulação com alta freqüência tem sido correlacionada com ativação predominante de fibras nervosas de grande calibre via padrão vibratório. A TENS tem sido muito utilizada para o alívio da dor nas neuropatias periféricas, especialmente nas clínicas de reabilitação. Há mais de 12 diferentes tipos de aparelhos para este objetivo. A aplicação recomendada é de 15 a 30 minutos, principalmente naqueles pontos dolorosos. O efeito placebo com TENS é similar em magnitude para aquele encontrado nas medicações analgésicas ou "adjuvantes".

Apesar de todas essas alternativas de tratamento, os resultados são, com certa freqüência, desanimadores. Por outro lado, às vezes há relatos de grande eficácia de certos procedimentos, mas que não apresentam uma reprodução de efeito sistematizado. Além de prescrevermos adequadamente o procedimento correto, devemos evitar o uso incorreto de drogas, e não devemos, nunca, esquecer o efeito placebo.

\section{Drogas que devem ser evitadas no tratamento da dor neuropática}

Benzodiazepinas e barbitúricos, efetivos para o tratamento de ansiedade, não apresentam propriedades analgésicas, por isso devem ser evitados no tratamento da dor crônica. Embora a dor aguda seja freqüentemente associada com sinais típicos de ansiedade, o tratamento deveria focar a causa básica de dor e o uso específico de agentes analgésicos.

\section{Resposta placebo}

Uma certa resposta terapêutica pode ser atribuída a uma droga específica ou a um procedimento quando ela é, de fato, devida a efeito placebo. A resposta placebo é muito comum. Assim, testar o paciente com solução salina, para verificar se a dor é real ou não, é ineficaz para fornecimento de informação útil. De fato, muitos pacientes com dor orgânica documentada obtêm alívio temporário sintomatológico após administração de placebo. Portanto, o uso de placebos para distinguir dor "psicogênica" de dor "real" deveria ser evitado.

\section{Psicoterapia}

Tratamento psiquiátrico é necessário para aqueles pacientes com disfunção psiquiátrica e também para aqueles com estado associado de depressão. Reconhecimento e orientação precoce dessas entidades oferecerão melhores resultados terapêuticos e evitarão excesso de uso de analgésicos. Uma doença psiquiátrica não diagnosticada mascarando uma pseudoneuropatia ou pseudomiopatia explica, em parte, a alta percentagem de insucesso terapêutico.

Quando nenhum quadro clínico geral, neurológico ou psiquiátrico é estabelecido, nós estamos convencidos de que é melhor deixar o paciente sofrer do que prescrever opiáceos ou indicar procedimentos cirúrgicos invasivos. Sabe-se que os hipocondríacos com dor, quando tratados com as medidas usuais, apresentam apenas os seus efeitos colaterais, sem qualquer tipo de melhora.

\section{PERSPECTIVAS DE USO DE DROGAS MAIS EFETIVAS}

Devido à ausência de uma droga mais efetiva para o tratamento de dor neuropática, a procura para um tratamento mais efetivo continua a ser um dos principais objetivos dos cientistas e da indústria farmacêutica. Dentre as drogas promissoras destacam-se:

Antagonista do receptor NMDA: o uso intratecal de antagonista do receptor NMDA (MK-801) encontrase relacionado com diminuição no mecanismo de transmissão da dor em animais e este achado tem contribuído para novas perspectivas no combate da dor em humanos ${ }^{6}$.

Agonista $\boldsymbol{\alpha}_{\mathbf{2}}$-adrenérgico (tizanidina): o uso intratecal de tizanidina $\left(\right.$ Sirdalud $\left.^{\circledR}\right)$ em ratos encontrase relacionado com a reversão dos estados de alodínia e de hiperpatia nos quadros de dor de origem neuropática e, dessa forma, sugere-se que ela pode ser de valor no tratamento de pacientes com essas síndromes clínicas ${ }^{7}$.

Conopeptídeos sintéticos ômega: o uso intratecal em ratos de SNX-111 e SNX-124, homólogos sintéticos dos ômega-conopeptídeos e potentes bloqueadores dos canais de cálcio, têm mostrado eficácia no tratamento de dores anormais que ocorrem após lesão nervosa ${ }^{12}$. 


\section{ABORDAGEM TERAPÊUTICA DA DOR NEUROPÁTICA NA CLÍNICA NEUROLÓGICA}

\section{Polirradiculeneurite inflamatória aguda (síndrome de Guillain-Barré)}

Esta síndrome congrega na realidade várias entidades cujo substrato fisiopatológico é um processo inflamatório de natureza autoimune que leva a uma desmielinização segmentar das raízes e nervos. Por isso, não raramente, dentre as manifestações clínicas destacase a presença de dor especialmente nos membros inferiores. Para o tratamento destaca-se o uso de plasmaférese, especialmente na fase inicial de instalação dos sintomas. Para o alívio da dor, é preconizado o uso de analgésicos comuns ou de AINH. Se, mesmo assim, não ocorrer alívio do quadro doloroso, indica-se o uso de carbamazepina ou de amitriptilina. A infusão de lidocaína intravenosa tem-se mostrado de grande utilidade nos casos de dor mais intensa e persistente.

\section{Síndrome radicular}

Hérnia de disco: embora também freqüente na região cervical, esta condição é a causa principal de dor crônica e intensa na região lombar e no membro inferior. Ocorre mais freqüentemente entre a $5^{\text {a }}$ vértebra lombar e a $1^{\mathrm{a}}$ sacral. A causa principal de protrusão discal é freqüentemente uma lesão por flexão, mas em considerável proporção dos pacientes não há qualquer referência de trauma. Um espirro, um simples solavanco ou outro movimento trivial pode ser a causa de protrusão do núcleo pulposo. Nos casos mais severos, o núcleo pode protrair-se através do ânulo fibroso ou tornar-se extruso e permanecer no canal medular como um corpo estranho. O material protraído freqüentemente causa irritação radicular. Nas fases mais agudas, o paciente deve realizar repouso na cama, preferencialmente absoluto, evitando qualquer movimento. A posição mais confortável é a de decúbito dorsal com as pernas semifletidas nos joelhos e nos quadris e com os ombros elevados sobre travesseiros para inibir a lordose lombar. A posição em decúbito lateral também pode apresentar-se confortável. Medidas físicas, tais como aplicação de gelo na fase aguda e calor local após o $3^{\circ}$ dia, diatermia, ou massagem, têm valor limitado. Medicamentos analgésicos, incluindo-se os opiáceos, devem ser dados liberalmente nos primeiros dias (codeína $30 \mathrm{mg}$ e aspirina $500 \mathrm{mg}$; meperidina $50 \mathrm{mg}$ ). Associadamente preconiza-se o uso de AINH como a indometacina (Indocid $^{\circledR} 50$ a $100 \mathrm{mg} / \mathrm{dia}$ ) ou ibuprofeno (Motrin ${ }^{\circledR}$,
Artril $^{\circledR} 300$ a 1200 mg/dia), ou de outros tipos de AINH, largamente utilizados. Caracteristicamente, este grupo farmacológico apresenta enfraquecimento da correlação dose-resposta a partir de determinada dose. Existe variação individual imprevisível na resposta aos diversos AINH e, assim, um determinado paciente pode ter alívio melhor alterando-se a substância dentro do mesmo grupo farmacológico. Os miorrelaxantes são também freqüentemente úteis, destacando-se o baclofen (Lioresal ${ }^{\circledR}$ ), carisoprodol (Dorilax ${ }^{\circledR}$, Mio-citalgan ${ }^{\circledR}$, Mioflex $^{\circledR}$, Tandrilax ${ }^{\circledR}$ ) e tizanidina $\left(\right.$ Sirdalud $\left.^{\circledR}\right)$. Cirurgia deve ser reservada para aquelas situações com disco extruso ou quando há alteração motora. Intensidade ou persistência da dor não devem guiar o médico para uma conduta cirúrgica. O resultado cirúrgico nessas situações é extremamente desanimador. Após 2 ou 3 semanas na cama, o paciente pode ser orientado a retornar a suas atividades gradualmente, freqüentemente com uma proteção de um colete para uso temporário. Exercícios apropriados devem ser instituídos para aumentar a força abdominal e dos músculos glúteos.

Em nossa experiência os pacientes mais difíceis de tratamento são aqueles com dor crônica na região lombar que já foram submetidos a uma ou mais lamnectomias ou a numerosos mielogramas com lipiodol, sobretudo no passado. O quadro doloroso torna-se intolerável e, freqüentemente, incapacita o paciente até para a realização de tarefas de vida diária.

Metástase: uma proporção significante de pacientes com dor secundária a metástase tem mais de um tipo de dor, e cada dor deve ter um mecanismo diferente de atuação médica. O tratamento envolve: 1) tratamento paliativo anticâncer, que envolve quimioterapia, manipulação hormonal, radioterapia ou cirurgia para diminuir ou parar o crescimento neoplásico; 2) tratamento analgésico, que dependerá da intensidade da dor. Para dor de intensidade leve sugere-se uso de analgésico não opióide (antiinflamatório não hormonal, aspirina, paracetamol). Para dor de intensidade moderada sugere-se uso combinado de analgésico não opióide com opióide fraco (codeína, dextropropoxifeno, oxicodone). Para casos de dor severa sugere-se uso combinado de analgésico não opióide e opióide forte (metadona, petidina, destromoramida e fentanil). Em todos os estágios podem-se usar drogas analgésicas auxiliares.

Herpes zoster: é bem conhecido que o herpes zoster pode afetar os segmentos lombo-sacros, causando uma dor tipo neurálgica e vesículas no território dos nervos envolvidos. A dor pode preceder em 1 a 2 dias a erupção das vesículas. Embora múltiplos agentes tenham sido utilizados para o tratamento desta infecção, eles não têm 
apresentado sucesso universal. O uso de corticóide na fase aguda está relacionado com menor freqüência de dor pós-herpética.

\section{Polineuropatia periférica}

Álcool: a associação entre alcoolismo e polineuropatia periférica tem sido relatada há vários anos. Uma das formas de apresentação clínica é como a síndrome dos "pés queimantes", caracterizada pela presença de dor severa queimante nas extremidades, mas com discreta alteração motora ou de reflexo. Os sintomas são piores à noite e interferem com o sono. Este quadro clínico é devido à deficiência nutricional. Um certo grupo de pacientes tem apresentado melhora após administração de vitamina B1 (tiamina) (Benerva ${ }^{\circledR}-300$ mg 2 vezes ao dia), outros apresentam melhora após administração de ácido nicotínico (Nicopaverina ${ }^{\circledR}$ ), mas a maioria não apresenta qualquer melhora com os tratamentos instituídos. A dor pode ser aliviada com o uso de drogas auxiliares.

Diabetes: diabetes causa uma neuropatia periférica dolorosa e incapacitante, muitas vezes resistente aos tratamentos com analgésicos e outras drogas auxiliares. O tratamento consiste no controle absoluto da hiperglicemia e as drogas recomendadas para alívio da dor incluem fenitoína, carbamazepina, fenotiazina, multivitaminas e antidepressivos tricíclicos. A associação de fenotiazina e antidepressivo tricíclico, especialmente flufenazina e amitriptilina, tem mostrado resultados satisfatórios em certa percentagem de casos. A carbamazepina geralmente é utilizada como droga de segunda escolha, mas também com resultados insatisfatórios em muitos casos. Temos demonstrado nesses casos melhora sintomatológica após uso de baclofen (Lioresal ${ }^{\circledR}$ ), uma droga de atuação gabaérgica, na dosagem de 20 a $30 \mathrm{mg}$ diariamente ${ }^{2}$. Recomenda-se a administração inicial com $10 \mathrm{mg}$ ao dia para evitar-se sensação de moleza e sonolência.

O uso de inibidores da aldose reductase (Alrestatin ${ }^{\circledR}$ ) não tem demonstrado uma melhora nítida na sintomatolgia dolorosa dos indivíduos portadores de neuropatia diabética.

Uremia: a dor, sintoma freqüente em pacientes urêmicos, é tratada semelhantemente àquela relacionada ao diabetes. Se há associação com síndrome das pernas inquietas, pode-se usar clonazepan (Rivotril ${ }^{\circledR}$ ) na dosagem de 2 a $4 \mathrm{mg} / \mathrm{dia}$. Esta é uma forma de neuropatia que pode ser revertida se um transplante de rim apresenta sucesso.

Tóxica: um grande número de drogas ou de substâncias químicas tóxicas empregadas no local de trabalho ou no meio ambiente têm sido implicadas como causas de neuropatia periférica, freqüentemente do tipo de axoniopatia distal, manifestando-se em muitas situações com dor ${ }^{10}$. O tratamento inicial consiste na suspensão absoluta da administração ou da exposição a esses agentes.

\section{Drogas}

Isoniazida (Hidrazida ${ }^{\circledR}$ ): a neuropatia dolorosa simétrica nos membros inferiores está relacionada com a inibição da fosforilação da piridoxina. A administração de 150 a $450 \mathrm{mg}$ de piridoxina (Vitamina B6) (Adermina ${ }^{\circledR}$ ) diariamente previne a instalação da neuropatia.

Metronidazole $\left(\right.$ Flagyl $\left.^{\circledR}\right)$ : um agente antibacteriano e antiprotozoário pode causar neuropatia periférica caracterizada por alterações sensitivas puras, às vezes irresponsiva aos tratamentos e irreversível.

Taxol: originário de uma planta alcalóide e usado como agente antineoplásico para tumores sólidos, está associado com neuropatia sensitiva caracterizada pela presença de parestesias e disestesias nas mãos e sobretudo nos pés. Administração de fator de crescimento nervoso pode retardar a apresentação da neuropatia em animais de experimentação e poderia ter algum efeito na neuropatia pelo taxol em humanos.

\section{Metais pesados}

Tálio: por causa de ausência de odor ou gosto, é um dos metais mais tóxicos. Sais de tálio são freqüentemente empregados em inseticidas e em raticidas e, não invariavelmente, são utilizados como veículo para suicídio. Pode ocorrer desenvolvimento de neuropatia caracterizada por comprometimento doloroso e ascendente dos membros inferiores. O tratamento inclui o uso de carvão ativado ou azul da Prússia.

Arsênico: neurotoxicidade do arsênico é freqüentemente relacionada com a ingestão de arsênico trivalente, principalmente nas tentativas de suicídio ou homicídio. A neuropatia desenvolve-se cerca de 10 dias a 3 semanas após a ingestão. Sintomas sensitivos aparecem mais precocemente, com freqüência com muita dor, seguindo-se déficit motor. A neuropatia progride sob uma forma ascendente, envolvendo inicialmente membros inferiores e depois os membros superiores, apresentando-se como a síndrome de Guillain-Barré. O tratamento envolve terapia com quelante ou com BAL, ou com penicilamina.

Intoxicação com alimentos e ervas: a tão chamada medicina alternativa ou não convencional é largamente 
utilizada em todo o mundo, incluindo-se os países mais desenvolvidos. Suplementos nutricionais e compostos com ervas são facilmente encontrados em supermercados, em farmácias e em lojas de produtos de alimentos "saudáveis". Alguns desses produtos, considerados até então seguros, eventualmente são neurotóxicos e causadores de neuropatia periférica.

Uma forma particular de neuropatia é descrita nos índios brasileiros do Alto Xingu. Os índios adolescentes do sexo masculino são submetidos a um ritual cultural característico onde ficam isolados, em um pequeno local dentro da casa de seus familiares, por um período variável, de meses a anos. Este período é marcado por muitas regras e tabus. O envolvimento do nervo periférico é relacionado com o uso de algumas plantas nativas, sob a forma de infusões ou de ungüentos. As principais características clínicas são taquicardia, sudorese, fraqueza muscular e alterações sensitivas, incluindo-se quadro doloroso sobretudo nos membros inferiores ${ }^{4}$.

\section{Polineuropatias determinadas geneticamente}

Amiloidose: a amiloidose familiar hereditária portuguesa, relacionada com mutação da transtiretina, manifesta-se clinicamente com envolvimento renal e de nervos periféricos. Há freqüentemente quadro doloroso, em especial nos membros inferiores, resistente à maioria dos medicamentos. A carbamazepina é um dos mais efetivos agentes terapêuticos. Pacientes submetidos a transplante hepático têm referido melhora no quadro doloroso.

Doença de Anderson-Fabry: caracteriza-se por dor, geralmente muito intensa e irresponsiva aos tratamentos habituais.

AIDS: neuropatia sensitiva afeta cerca de $30 \%$ dos pacientes com AIDS, especialmente nas fases tardias, quando há uma imunossupressão severa. Em aproximadamente $1 / 3$ desses pacientes há associação de quadro doloroso, especialmente na sola dos pés, também resistente às medidas terapêuticas tentadas. Os analgésicos narcóticos, incluindo-se o fentanil transdérmico (Duragesic ${ }^{\circledR}, 25-100 \mu \mathrm{g} / \mathrm{h}$ ), apresentam os melhores efeitos, mas não raramente os pacientes apresentam intolerância aos medicamentos, mesmo se usados em dosagens menores, e a regra é o não alívio sintomatológico.

Citomegalovírus (CMV): é uma infecção viral oportunística que ocorre frequientemente em indivíduos com AIDS em estágio avançado. Caracteristicamente, manifesta-se com síndrome de cauda eqüina assimétrica, predominantemente motora, associando-se dor lombar com irradiação para uma da pernas, seguindo-se incontinência urinária. Ganciclovir (dose de ataque de $5 \mathrm{mg} / \mathrm{kg}$ por dose, duas vezes ao dia, por 14 a 21 dias, seguindo-se de manutenção de $5 \mathrm{mg} / \mathrm{kg} 5$ a 7 vezes por semana), um agente antiviral efetivo contra CMV, tem permitido estabilização clínica ou até melhora.

Neuropatia sensitiva carcinomatosa: relacionada freqüentemente com carcinoma de pulmão de células pequenas (oat cell) e, menos freqüentemente, com carcinoma de esôfago, mama, ovário, rim e fígado, caracteriza-se clinicamente pelo aparecimento de disestesia nos membros, associada a ataxia, que pode preceder a manifestação clínica do tumor primário. Algumas reportagens demonstram uma melhora neurológica após a remoção ou tratamento quimioterápico do tumor. Embora imunopatologicamente mediada, a maioria dos casos não apresenta qualquer melhora, e neuropatia continua a progredir mesmo com uso de agentes citotóxicos, plasmaférese, administração de gamaglobulina intravenosa. A dor neuropática pode ser incapacitante. Pode ser aliviada com antidepressivos tricíclicos em altas doses, mas freqüentemente há necessidade de uso de opiáceos.

\section{Mononeuropatias isoladas e múltiplas}

Colagenoses com arterite: a angiopatia necrotizante associada com artrite reumatóide, poliarterite nodosa, granulomatose de Wegner, Churg-Strauss e síndrome de Sjögren é tipicamente caracterizada por quadro de mononeuropatia múltipla afetando os nervos dos membros superiores e inferiores. O quadro doloroso é freqüentemente resistente aos tratamentos sintomatológicos usuais. Entretanto, o alívio sintomatológico pode ser alcançado com o tratamento da angiopatia com corticosteróide ou com imunossupressor. Particularmente, a sintomatologia dolorosa na síndrome de Sjögren é resistente mesmo ao uso desses medicamentos. Temos acompanhado, contudo, uma paciente que apresentou melhora sintomatológica somente após a introdução de ciclofosfamida (Enduxan ${ }^{\circledR} 100 \mathrm{mg} / \mathrm{dia}$ ). O uso de corticosteróide, de azatioprina e de metotrexato não proporcionou qualquer alívio na dor, que era extremamente intensa e incapacitante, dos membros inferiores. A melhora clínica encontrou-se intimamente relacionada com o uso do imunossupressor, uma vez que logo após a sua retirada, devido a alterações hepáticas transitórias, a dor recidivou-se.

Meralgia parestésica: a dor ou dormência na face lateral da coxa, decorrente da compressão do nervo femorocutâneo (nervo cutâneo lateral da coxa), às vezes 
tem remissão espontânea, mas não invariavelmente a sintomatologia é persistente, mesmo com a utilização de várias medidas terapêuticas, como exposto anteriormente.

\section{SUMMARY}

\section{A Therapeutic Approach to Neuropathic Pain}

In this review the authors describe the drugs and procedures most commonly used for the relief of pain in neurology practice, and they present a practical approach for the management of pain encountered in the many peripheral neuropathies.

\section{KEY WORDS}

Pain, analgesics, peripheral neuropathy.

\section{Referências}

1. Adams, R.D.; Victor, M. In: Adams, R.D.; Victor, M. Principles of Neurology. 3a ed. New York, McGraw-Hill, 1986, p. 101-113.

2. Anguinah, R.; Oliveira, A.S.B.; Gabbai, A.A. Efect of baclofen on pain in diabetic neuropathy. Muscle \& Nerve, 958-959, 1994.

3. Corrêa, C.F.; Teixeira, M.J.; Oliveira Jr., J.O.; Pimenta, C.A.M. Sistemas implantáveis de infusão de drogas em doentes com dor oncológica de difícil controle. Arq Bras Neurocirurg, 13: 123-128, 1994.

4. Gabbai, A.A.; Schmidt, B.; Oliveira, A.S.B.; Pinto, N.R.S. An original peripheral neuropathy associated with a seclusion rite in male adolescent Brazilian Indians. Muscle \& Nerve, 9(suppl 5): 123, 1986.

5. Gozzani, J.L.; Pagura, J.R. Tratamento da dor. In: Prado, F.C.;
Ramos, J.; Valle, J.R. (eds.) Atualização Terapêutica: manual prático de diagnóstico e tratamento. $17^{\underline{a}}$ ed. São Paulo, Artes Médicas, 1995, p. 1172-1175.

6. Lee, Y.W.; Yaksh, T.L. Analysis of drug interaction between intrathecal clonidine and MK-801 in peripheral neuropathic pain rat model. Anestesiology, 82: 741-748, 1995.

7. Leiphart, J.W.; Dills, C.V.; Zikel, O.M.; Kim, D.L.; Levy, R.M. A comparison of intrathecally administered narcotic and nonnarcotic analgesics for experimental chronic neuropathic pain. J Neurosurg, 82: 595-599, 1995.

8. Ochoa, J.L. Essence, investigation, and management of "neuropathic" pains: hopes from acknowledgement of chaos. Muscle \& Nerve, 16: 997-1008, 1993.

9. Payne, R.; Pasternak, G.W. In: Principles of drug therapy in neurology. FA Davis Company, Philadelphia, 1992.

10. Schaumburg, H.H.; Spencer, P.S. Neuropathies associated with chemicals, metals and drugs. In: Dyck, P.J.; Thomas, P.K.; Lambert, E.H.; Bunge, R. Peripheral Neuropathy. $2^{\mathrm{a}}$ ed. Philadelphia, 1984, p. 2115-2179.

11. Stanton-Hicks, M.; Hänig, W.; Hassenbusch, S.; Haddox, J.D. et al. Reflex sympathetic dystrophy: changing concepts and taxonomy. Pain, 63: 127-133, 1995.

12. Xiao, W.H.; Bennett, G.J. Synthetic omega-conopeptides applied to the site of nerve injury suppress neuropathic pains in rats. J Pharmacol Exp Ther, 274: 666-672, 1995.

\section{Endereço para correspondência:}

Universidade Federal de São Paulo

Escola Paulista de Medicina

Rua Botucatu, 740

CEP 04023-900 São Paulo (SP)

Caixa Postal 20207 